\title{
Biographisches Handbuch \\ der deutschsprachigen Emigration nach 1933
}

Herausgegeben vom

Institut für Zeitgeschichte München und von der

Research Foundation for Jewish Immigration, Inc., New York, unter der Gesamtleitung von

Werner Röder und Herbert A. Strauss

\section{International Biographical Dictionary \\ of Central European Emigrés 1933-1945}

Sponsored by

Research Foundation for Jewish Immigration, Inc., New York, and Institut für Zeitgeschichte München.

General editors

Herbert A. Strauss and Werner Röder 



\section{Biographisches Handbuch der deutschsprachigen Emigration nach 1933}

\section{Band III \\ Gesamtregister}

Unter der Leitung von Werner Röder zusammengestellt von

Sybille Claus, Daniel Niederland und Beatrix Schmidt Leitung der Redaktion: Sybille Claus

\section{International Biographical Dictionary of Central European Emigrés 1933-1945 \\ Volume III Index}

Under the direction of Werner Röder compiled by

Sybille Claus, Daniel Niederland and Beatrix Schmidt Managing Editor: Sybille Claus

$\mathrm{K} \cdot \mathrm{G} \cdot$ Saur München $\cdot$ New York $\cdot$ London $\cdot$ Paris 1983 
CIP-Kurztitelaufnahme der Deutschen Bibliothek

Biographisches Handbuch der deutschsprachigen Emigration nach 1933 - International biographical dictionary of central European émigrés 1933 - 1945 / hrsg. vom Inst. für Zeitgeschichte München u.

von d. Research Foundation for Jewish Immigration, Inc., New York, unter d. Gesamtleitung von

Werner Röder u. Herbert A. Strauss. - München ;

New York ; London ; Paris : Saur

NE: Röder, Werner [Hrsg.]; Institut für

Zeitgeschichte (München); PT

Bd. 3. Gesamtregister / unter d. Leitung von

Werner Röder zsgest, von Sybille Chus ... -

1983.

ISBN 3-598-10090-6

NE: Claus, Sybille [Mitverf.]

Copyright (C) 1983 by K. G. Saur Verlag KG, München

Printed in the Federal Republic of Germany

Alte Rechte vorbehalten.

Dieses Werk - oder Teile daraus - darf nicht vervielfältigt,

in Datenbanken gespeichert oder in irgendeiner Form - elektronisch, photomechanisch, auf Tonträger oder sonstwie übertragen werden ohne die schriftiche Genehmigung des Verlags.

Computer-controlled phototypesetting and

Digiset Data preparation and automatic data processing

Satz-Rechen-Zentrum Hartmann + Heenemann, Berlin

Drack/Binden: Friedrich Pustet, Regensburg

ISBN 3-598-10087-6 (Gesamt)

ISBN 3-598-10090-6 (Band 3) 